\title{
Hot stamping of an Al-Li alloy: a feasibility study
}

\author{
Haoxiang Gao ${ }^{1}$, Tianxin Weng ${ }^{1}$, Jun $\mathrm{Liu}^{1}$, Chang $\mathrm{Li}^{1}$, Zhiqiang $\mathrm{Li}^{2}$, and Liliang Wang ${ }^{1, *}$ \\ 1 Department of Mechanical Engineering, Imperial College London, London SW7 2AZ, United Kingdom \\ 2 AVIC Beijing Aeronautical Manufacturing Technology Research Institute, Beijing 100024, China
}

Received 30 September 2015 / Accepted 28 February 2016

\begin{abstract}
The feasibility of forming a third generation aluminium-lithium alloy (AA2060) into a complex shaped panel component, was studied by using an advanced forming technology called solution heat treatment, cold die forming and in-die quenching $\left(\mathrm{HFQ}^{\mathrm{a}}\right)$ process. The main challenges using HFQ technology to form complex shaped AA2060 component was to find out optimum forming parameters, such as forming temperature, forming speed, lubrication condition and blank holding force. In this paper, the optimum forming temperature was mainly concerned. The flow stresses of AA2060 were obtained at different temperatures ranging from 350 to $520{ }^{\circ} \mathrm{C}$ at the strain rate of $2 \mathrm{~s}^{-1}$. The suitable temperature to achieve the adequate ductility was found at $470{ }^{\circ} \mathrm{C}$. By forming the AA2060 blanks at the optimum forming temperature, experimental results exhibited the feasibility for forming complexshaped AA2060 components. The formed components were analysed through strain measurements. The post-form mechanical properties of AA2060 were assessed using hardness and tensile tests.
\end{abstract}

Key words: Hot stamping, Aluminium lithium, Ductility, Age hardening, Solution heat treatment

\section{Introduction}

In order to produce light-weight and fuel efficient aircraft, the aerospace industry has experienced increasing demand for advanced aluminium lithium alloys. Applications of the third generation of Al-Li alloy used industry include Fuselage skins of the Space Shuttle, upper and lower wing covers [1]. The third generation Al-Li alloy, such as AA2060, not only provides outstanding strength, toughness, stiffness and high temperature performance, but also gives superior corrosion resistance and weight saving [2]. Although the Al-Li alloy can offer enhanced properties compared to conventional aluminium alloys, the manufacturing of panel components through cold stamping of Al-Li alloy still experiences significant challenges due to its poor ductility at room temperature [3]. In order to form Al-Li alloy components, extensive research has focused on the hot workability of the alloy by investigating process mapping [4-6]. It has been found that superplastic forming technique (SPF) is one of the most feasible forming techniques to produce complex-shaped Al-Li sheet components. However, the forming speed of SPF is fairly low and the severe localised thinning is not avoidable. In order to produce Al-Li panel components more efficiently, advanced forming technologies have been studied [7, 8].

\footnotetext{
*Corresponding author: liliang.wang@imperial.ac.uk

${ }^{\text {a }} \mathrm{HFQ}^{\circledR}$ is a registered trademark of Impression Technologies Ltd.
}

The solution heat treatment, forming, and in-die quenching (HFQ) process is a patented technology developed at Imperial College for processing sheet aluminium alloy. The HFQ forming technology can produce complex, deep drawn forms with excellent post-form material properties. A post-form artificial ageing process is usually required to retain the full mechanical properties of the alloy [9]. In the HFQ forming process, a blank is firstly heated up to its solution heat treatment (SHT) temperature to dissolve the alloying elements, or soluble precipitates into the aluminium matrix $[10,11]$. The hot blank is then transferred to the cold die which is immediately closed to form the blank. During quenching, the formed component is held within the cold tool to rapidly cool down the blank to room temperature. The fast pace of the process allows a supersaturated solid solution (SSSS) to be obtained [12]. Extensive research work has been conducted on the effects of solutionising time and quenching rate on the HFQ forming process, which verified that the high strength can be achievable by following an appropriate ageing process $[13,14]$.

In recent years, HFQ forming technology has been applied to a number of alloys including AA5XXX $[15,16]$, AA6XXX [17] and AA7XXX. Investigations on a similar alloy, AA2024, under HFQ conditions have found that the suitable temperature to obtain high ductility is below the SHT temperature [17]. In order to avoid the melt of low eutectic melting phase, AA2024 is first formed at a temperature with the adequate ductility. 
Table 1. Chemical composition of AA2060 blank.

\begin{tabular}{lccccccc}
\hline Composition & $\mathrm{Li}$ & $\mathrm{Mg}$ & $\mathrm{Cu}$ & $\mathrm{Ag}$ & $\mathrm{Mn}$ & $\mathrm{Zn}$ & $\mathrm{Al}$ \\
\hline$(\mathrm{wt} \%)$ & $0.6-0.9$ & $0.6-1.1$ & $3.4-3.5$ & $0.05-0.5$ & $0.1-0.5$ & $0.3-0.5$ & $\mathrm{Bal}$ \\
\hline
\end{tabular}

(a)

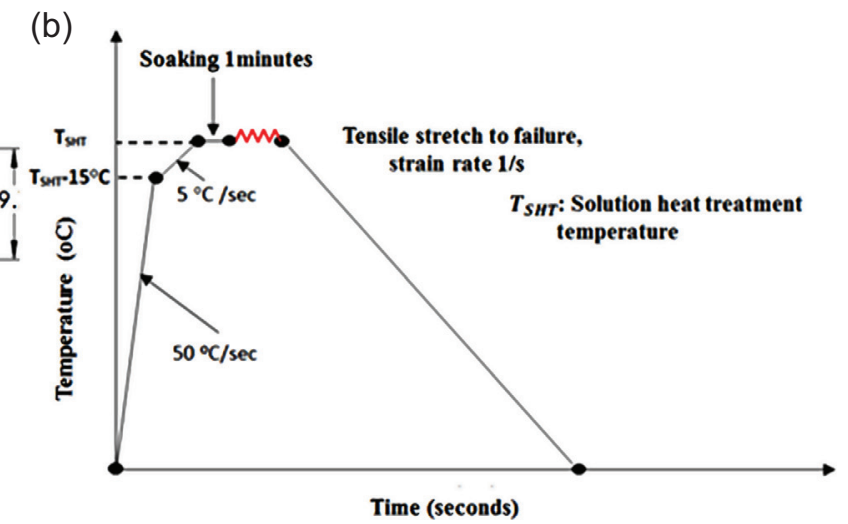

Figure 1. (a) Tensile specimen dimensions, (b) programmed heating profile for tensile test.

After the first stage forming, the subsequent second stage forming following the processing routes of SHT, cold die quenching and artificial aging was conducted to obtain the optimum strength of the part. The overall forming process is called two-stage HFQ [10].

The aim of this work is to form a complex-shaped wing stiffener component using AA2060 under HFQ conditions. Uniaxial tensile tests have been conducted to identify the optimum forming temperature. The strain distribution within the final product was examined using ARGUS system. The mechanical properties of AA2060 before and after HFQ forming have been assessed by comparing the hardness and tensile strengths.

\section{Experimental details}

\subsection{Material}

The $2 \mathrm{~mm}$ thick AA2060 blanks used in this study were supplied by Beijing Aeronautical Manufacturing Technology Research Institute (BAMTRI), in the T8 condition (Solution heat treated, cold worked and artificially aged). The chemical composition of AA2060 is shown in Table 1.

\subsection{Uniaxial tensile tests}

The dog bone shaped specimens for the uniaxial tensile tests were prepared by a laser cutter with the gauge length parallel to the rolling direction, with detailed dimensions as shown in Figure 1a. Each tensile test specimen was stretched to failure at the constant strain rate of $2 / \mathrm{s}$. The uniaxial tensile tests were conducted on a Gleeble 3800 thermo-mechanical simulator at different temperatures. The Gleeble tensile tests were performed in two stages: (i) the heating stage and (ii) mechanical tensile to failure stage. To avoid over-heating issues, each specimen was heated up to a temperature $25^{\circ} \mathrm{C}$ lower than the target temperature, at a heating rate of $50{ }^{\circ} \mathrm{C} / \mathrm{s}$ and then heated to the target temperature at a rate of $5{ }^{\circ} \mathrm{C} / \mathrm{s}$ in the second stage. After heating stage, the hot specimen was soaked for $1 \mathrm{~min}$ in order to stabilize the temperature within the gauge length area. The overall heating evolution is shown in Figure 1b. Figure 2 shows the photographs of AA2060 tensile test specimens and the testing system equipment for tensile test.

\subsection{Forming tests}

The AA2060 blanks were formed using an existing tool, designed and manufactured by the authors' group, to produce wing stiffener components under the two-stage HFQ forming conditions. The experiment set up is fully described by EL Fakir et al. [11]. Figure 3 shows the stamping tool used to form the wing stiffener component.

Forming tests were conducted at a speed of $250 \mathrm{~mm} / \mathrm{s}$ and at a temperature of $470{ }^{\circ} \mathrm{C}$. The specimen size is $200 \times 65 \times 2$ in $\mathrm{mm}$. For the first stage, the specimen was heated up to the forming temperature $\left(470{ }^{\circ} \mathrm{C}\right)$ which is below the SHT temperature (typically around $520^{\circ} \mathrm{C}$ ) of AA2060 [18]. After the hot blank was transferred to the cold tool, the stamping process was activated immediately. The transfer time from the furnace to the cold die was controlled to be around $10 \mathrm{~s}$. The aim of first stage is to form the Al-Li alloy with optimum geometrical features. In the second stage, the formed specimen was transferred to the furnace and re-heated up to its SHT temperature $\left(520^{\circ} \mathrm{C}\right)$. The objective of second stage is to achieve the high strength of alloy. After soaking at the SHT temperature for $1 \mathrm{~min}$, the specimen was placed back to the cold die and subsequently quenched to room temperature by the cold die. The objective of second stage is to achieve the high post strength of alloy. The forming temperature was monitored by attaching a thermocouple wire on the specimen, thus the temperature history was recorded during the whole process. Finally, the formed part was artificially aged at $180^{\circ} \mathrm{C}$.

An optical 3D forming analysis system ARGUS has been employed to measure the strain distributions of the formed 
(a)

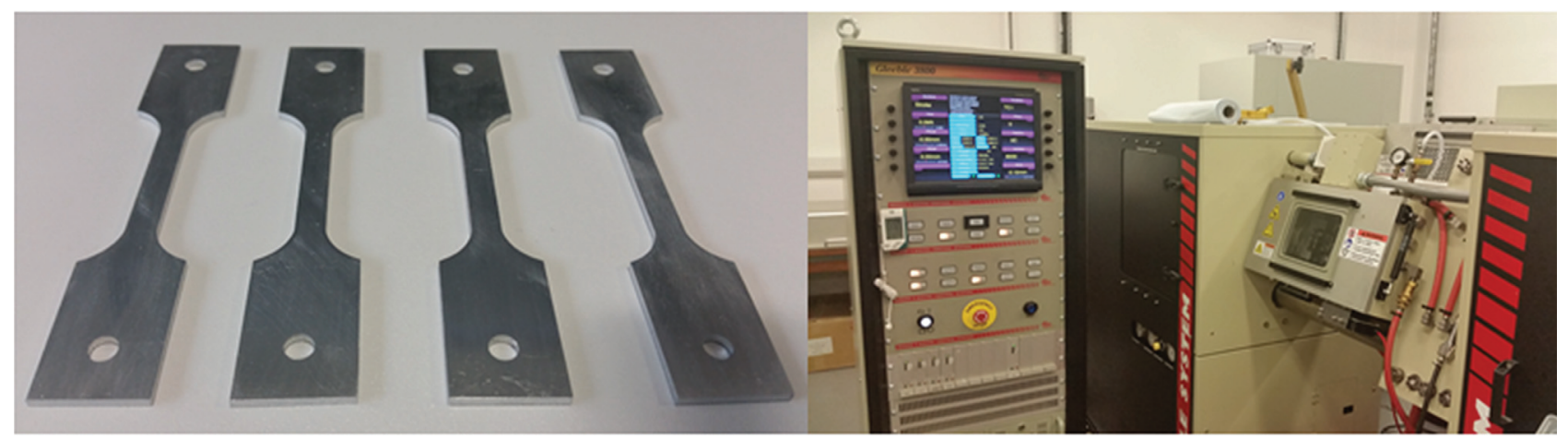

Figure 2. (a) Photographs of the tensile test specimens, (b) the testing system equipment.

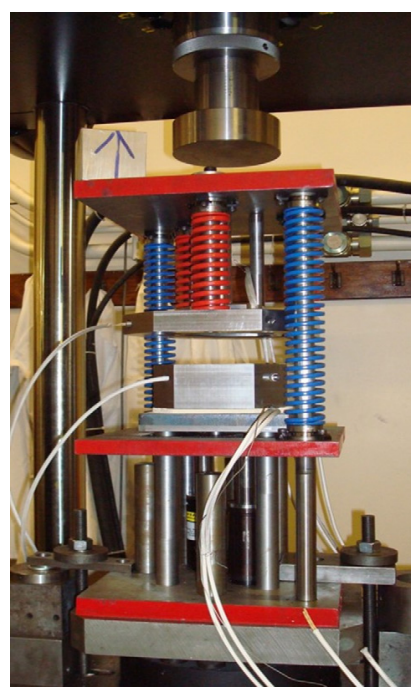

Figure 3. Stamping tool used.

parts. Vickers hardness tests were conducted to determine the material strength of the artificial aged alloy at different ageing times.

(a)

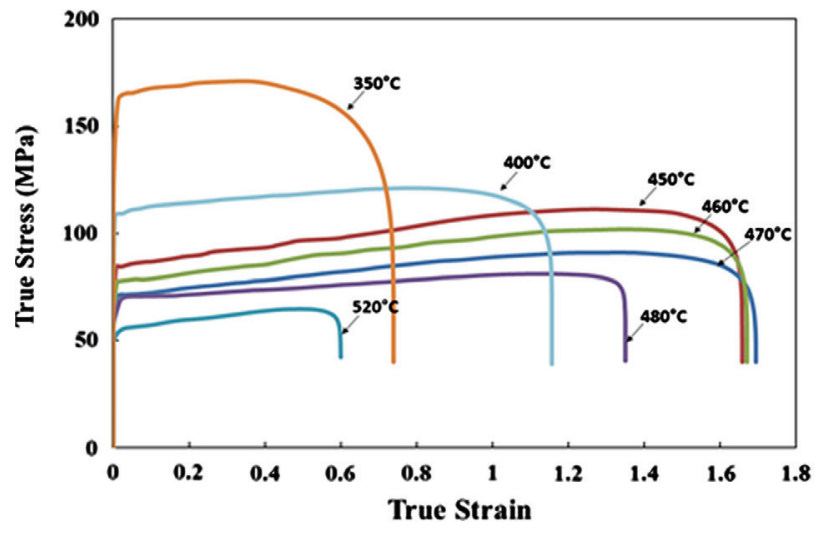

\section{Results and discussion}

\subsection{Effects of temperature on the strength and ductility of AA2060}

Figure 4a shows the flow stress curves of AA2060 obtained at different temperatures ranging from 350 to $520{ }^{\circ} \mathrm{C}$.

In Figure 4b, the elongations-to-failure of AA2060 at different temperatures were presented. The peak value of the strain to failure was observed at $470{ }^{\circ} \mathrm{C}$, which is in excess of 1.6 (true strain), while it is only 0.6 at the SHT temperature $\left(520{ }^{\circ} \mathrm{C}\right)$. From $350{ }^{\circ} \mathrm{C}$ to $470{ }^{\circ} \mathrm{C}$, the ductility of AA2060 increases with increasing temperature. This is explained by the thermal activated deformation mechanism, it enhanced the mobility of the atom and dislocations, and hence the material becomes more ductile. However, the ductility decreased remarkably as the temperature was above $470{ }^{\circ} \mathrm{C}$. The elongation-to-failure at $520^{\circ} \mathrm{C}$ is about one-third of its peak value, and a similar trend was found for AA2024 [2, 17]. For the typical heat treatable aluminium alloys used in the automotive industry (e.g. AA6XXX), the soluble precipitates and inclusions dissolve into the matrix at SHT temperature. As a result, the ductility of the alloys attains a higher level than that at lower temperatures due to less obstacle barriers to the

Figure 4. (a) Flow stress curves of AA2060 at different temperatures at the strain rate of $2 \mathrm{~s}^{-1}$, (b) ductility of AA2060 at different temperatures.

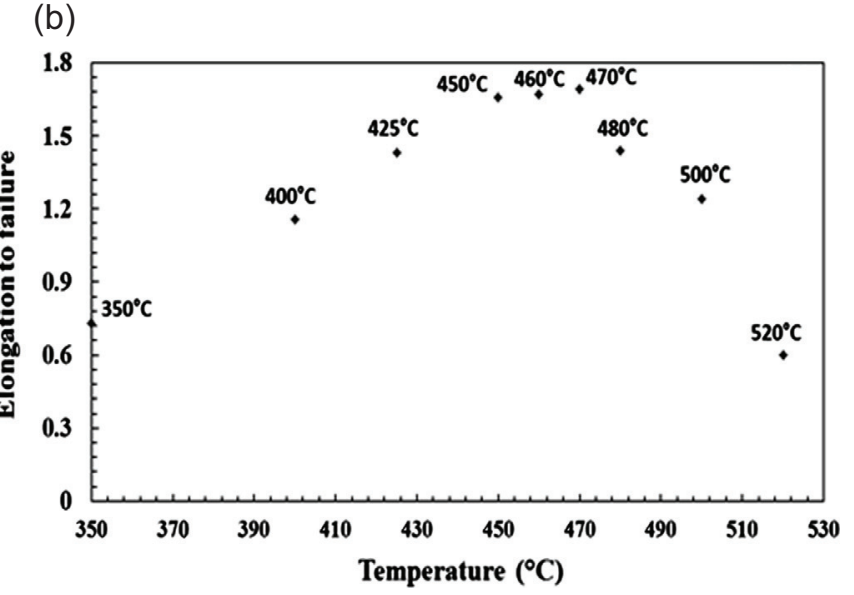




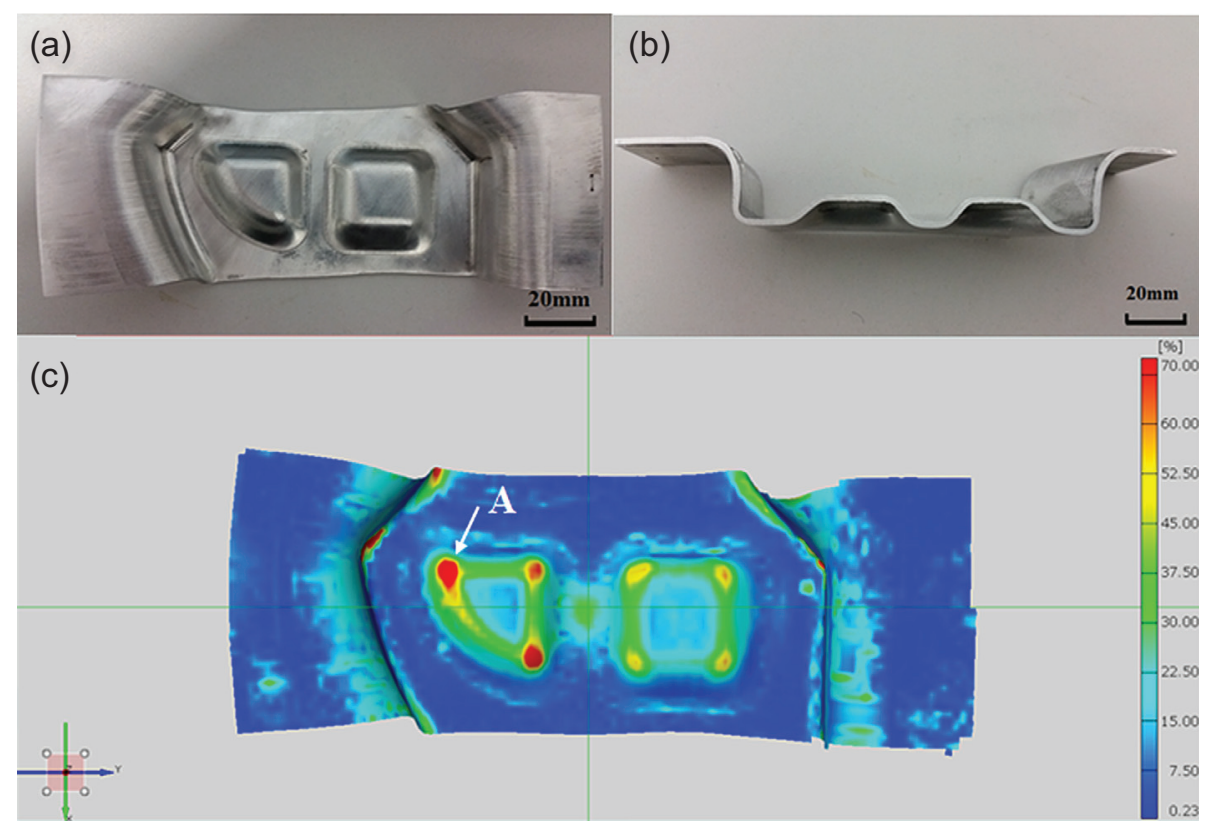

Figure 5. A wing stiffener component formed by the two-stage HFQ process: (a) top view, (b) cross section view, and (c) measured equivalent strain distribution within the formed wing stiffener.

dislocation motion during deformation. However, it has been reported that the reduced ductility in AA2024 is due to the presence of low eutectic melting phase at the SHT temperature [17]. AA2060 and AA2024 are both Al-Cu based alloys. Hence, as a similar Al-Cu based alloy, the melt of low eutectic melting phase in AA2060 could be one of the reasons to explain the poor ductility at $520{ }^{\circ} \mathrm{C}$ [18]. According to the tensile test results, the suitable forming temperature of AA2060 is $470{ }^{\circ} \mathrm{C}$. In order to avoid the premature fracture and remain the good ductility of material, the temperature used in the forming test was set to $470{ }^{\circ} \mathrm{C}$.

\subsection{HFQ forming of wing stiffener components}

Figures $5 \mathrm{a}$ and $5 \mathrm{~b}$ show sections of a wing stiffener panel formed using HFQ process. Complex features have been formed successfully. Figure $5 \mathrm{c}$ shows the von-Mises equivalent strain distributions of the part, it is observed that the large plastic deformation occurs in the vicinity of the complex geometric features, with peak engineering strain of above $70 \%$ in Region $\mathrm{A}$.

\subsection{Age hardening of AA2060}

Artificial aging behaviours of AA2060 with and without deformation were studied using hardness test. It has been reported that the typical ageing temperature for Al-Li alloy is $160-190{ }^{\circ} \mathrm{C}$ [2]. The hardness of as received AA2060-T8 material was $170 \mathrm{HV}$. After SHT and subsequent quenching, both materials were in supersaturated solid solution (SSSS) state, and the hardnesses were around $80 \mathrm{HV}$. Figure 6 shows the hardness evolution of undeformed material and HFQ formed part at different lengths of artificial ageing time when the artificial aging temperature was $180^{\circ} \mathrm{C}$. As the artificial ageing progressed, the hardness of the undeformed material

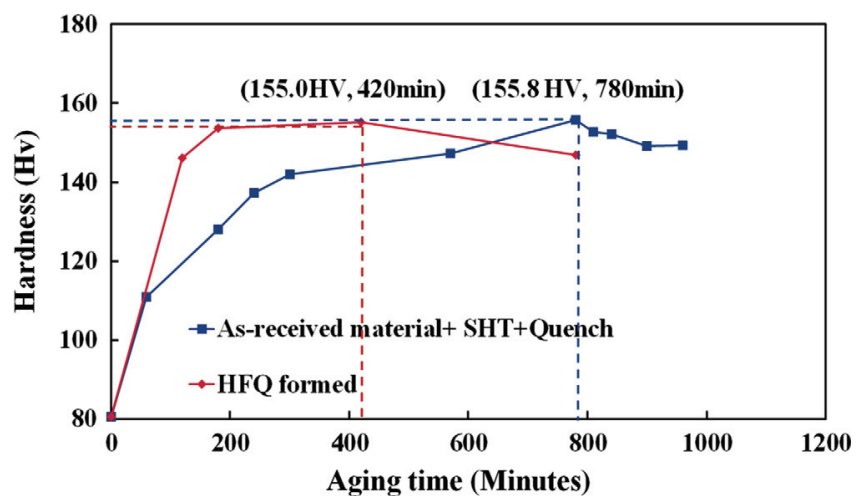

Figure 6. Age hardening of AA2060 at $180{ }^{\circ} \mathrm{C}$ with and without deformation.

and HFQ formed part increased gradually until their peak values of $155.8 \mathrm{HV}$ at $780 \mathrm{~min}$ and $155.0 \mathrm{HV}$ at $420 \mathrm{~min}$ respectively. It indicates that the artificial aging time required for the HFQ formed component to obtain the maximum strength is shortened by $50 \%$ than that for the undeformed material. Dislocations induced by deformation may have accelerated the kinetics of artificial ageing process [19].

\subsection{Post-form strength of AA2060}

Figure 7 shows the stress-strain curves of AA2060, which were obtained from the fully aged HFQ formed component using the optimised aging conditions $\left(180^{\circ} \mathrm{C}, 420 \mathrm{~min}\right)$ and the as-received material (AA2060-T8). The yield stress of the HFQ formed part is $358 \mathrm{MPa}$, which is approximately $88 \%$ of the as-received material $(407 \mathrm{MPa})$. The ultimate tensile strength and ductility of the HFQ formed part are $444 \mathrm{MPa}$ and $10.4 \%$, which can reach to $95.4 \%$ and $87.8 \%$ of the 


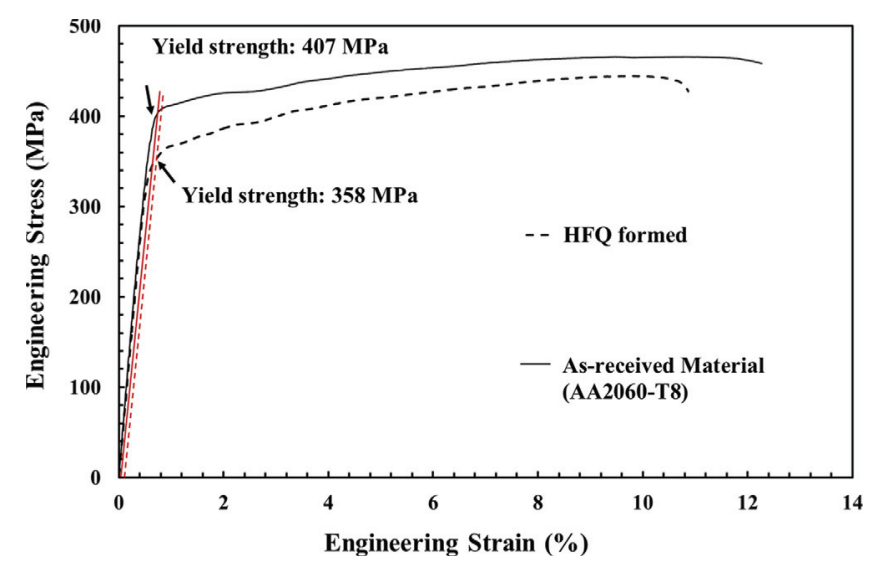

Figure 7. The comparison of stress-strain curves between the fully aged HFQ formed component $\left(180{ }^{\circ} \mathrm{C}, 420 \mathrm{~min}\right)$ and the as-received material (AA2060-T8).

as-received material (AA2060-T8) respectively (465 MPa, $12.3 \%$ ). Hence the full mechanical properties of AA2060 can be retained after HFQ forming.

\section{Future work}

In the present work, the Gleeble tensile test was conducted, the optimum forming temperature has been found out. However, some forming parameters still need further optimization for forming AA2060 complex shape component through HFQ technology, such as the forming speeds and blank holding force. For the future work, the formability test will be conducted in order to investigate the formability of AA2060 at different forming speeds.

\section{Conclusions}

The AA2060 wing stiffener components have been formed successfully using a two-stage HFQ forming technique. Based on the tensile test results, the material was firstly formed at the temperature of $470{ }^{\circ} \mathrm{C}$ to obtain a good formability, and then the formed part was solution treated at $520^{\circ} \mathrm{C}$ and subsequently in-die quenched followed by an artificial ageing process. The optimum artificial aging time and aging temperature of HFQ formed component are $420 \mathrm{~min}$ and $180{ }^{\circ} \mathrm{C}$. The artificial aging time of HFQ formed component is $50 \%$ shorter than that of the raw material $(780 \mathrm{~min})$. The difference in yield strength, ultimate tensile strength and ductility of AA2060 before and after HFQ are rather minor, suggesting that the HFQ process is able to retain the full mechanical properties of the aluminium alloy.
Acknowledgements. The strong support from Aviation Industry Corporation of China (AVIC) Beijing Aeronautical Manufacturing Technology Research Institute for this funded research is much appreciated. The research was performed at the AVIC Centre for Structural Design and Manufacture at Imperial College London.

\section{References}

1. ALCOA, Advancing Each Generation, Alcoa, www.alcoa.com accessed 03 March 2015.

2. N.E. Prasad, A.A. Gokhale, R.J.H. Wanhill (Eds.), Aluminium lithium alloys: processing, properties, and applications, Butterworth-Heinemann, Oxford, UK, 2013, p. 63.

3. L. Ma, J. Cui, Ad. Performance Mater 4 (1997) 105-114.

4. S.S. Menon, H.J. Rack, Proceeding of the Fourth Int. Conference 2 (1994) 230-237.

5. M. Niikura, K. Takahashi, C. Couchi, Hot deformation behaviour in Al-Li-Cu-Mg-Zr alloys III, Proceeding of the Third International Conference on Aluminium-Lithium Alloys, The Institute of Metals, London, UK, 1985, pp. 213-221.

6. A.A. Gokhale, V. Eswara Prasad, N. Chakravorty, C.R. Prasad, Proceeding of the Fourth Int. Conference, Process maps for aluminium lithium alloys 2 (1994) 242-249.

7. J. Wadsworh, I.G. Palmer, D.D. Crooks, Scr. Metall. 17 (1983) 347-352.

8. H.J. Koh, N.J. Kim, S. Lee, E.W. Lee, Mater. Sci. Eng. 256 (1998) 208-213.

9. R.P. Garrett, J. Lin, T.A. Dean, Int. J. Plast. 21 (2005) 1640-1657.

10. J. Lin, D. Balint, L. Wang, T.A. Dean, A.D. Foster, Method of forming a component of complex shape from sheet material, Patent GB2473298-A; 52 WO2011058332-A1; CA2720808Al, 2011.

11. O.EL. Fakir, L. Wang, D. Balint, J.P. Dear, J. Lin, T.A. Dean, Inter. J. Mach. Tool. Manu. 87 (2014) 39-48.

12. R.P. Garrett, J. Lin, T.A. Dean, Int. J. Plast. 21 (2005) 1640-1657.

13. M.F. Ashby, Engineering materials 2: an introduction to microstructures, processing and design. 3rd ed., Elsevier Butteworth-Heinemann, Oxford, 2006.

14. X. Fan, Z. He, S. Yuan, K. Zheng, Mater. Sci. Eng. A 573 (2013) 154-160.

15. X.B. Fan, Z.B. He, S.J. Yuan, P. Lin, Mater. Sci. Eng. A: Struct. Mater. Prop. Microstruct. Process. 587 (2013) 221-227.

16. M.S. Mohamed, A.D. Foster, J. Lin, D.S. Balint, T.A. Dean, Int. J. Mach. Tool. Manu. 53 (2012) 27-38.

17. L. Wang, M. Strangwood, D. Balint, J. Lin, T.A. Dean, Mat. Sci. Eng. A Struct. 528 (2011) 2648-2656.

18. N.E. Prasad, A.A. Gokhale, R.J.H. Wanhill (Eds.), Aluminium lithium alloys: processing, properties, and applications, Butterworth-Heinemann, Oxford, UK, 2013, p. 80.

19. M.S. Mohamed, J. Lin, L. Wang, D. Balint, Int. H. Treat Sur. Engineering 4 (2010) 160-165.

Cite this article as: Gao H, Weng T, Liu J, Li C, Li Z \& Wang L: Hot stamping of an Al-Li alloy: a feasibility study. Manufacturing Rev. $2016,3,9$. 